\title{
Phenolic Contents of Different Potato Genotypes Grown in the Central Northern Region in Turkey
}

\author{
Yasin Bedrettin Karan ${ }^{1, a, *}$, Tarık Balkan ${ }^{2, b}$, Ramazan Erenler $^{3, c}$ \\ ${ }^{1}$ Department of Field Crop Science, Faculty of Agriculture, Tokat Gaziosmanpasa University, 60250 Tokat, Turkey \\ ${ }^{2}$ Department of Plant Protection, Faculty of Agriculture, Tokat Gaziosmanpasa University, 60250 Tokat, Turkey \\ ${ }^{3}$ Department of Chemistry, Faculty of Science and Literature, Tokat Gaziosmanpasa University, 60250 Tokat, Turkey \\ *Corresponding author
}

\begin{tabular}{|c|c|}
\hline A R T I C L E I N F O & B S T R A C T \\
\hline $\begin{array}{l}\text { Keywords: } \\
\text { Solanum tuberosum L. } \\
\text { Phenolic compounds } \\
\text { LC-MS/MS }\end{array}$ & $\begin{array}{l}\text { Potato (Solanum tuberosum L.) is one of the most significant vegetable crops for humans along with } \\
\text { corn, wheat, and rice. In this study, quantitative analysis of phenolic compounds was carried out for } \\
21 \text { promising potato clones and three commercial cultivars. LC-MS/MS was used for the chemical } \\
\text { analyses. The TOGU } 3 / 518 \text { clone had the highest level of } 4 \text {-hydroxybenzoic acid as } 138.51 \pm 7.35 \\
\mu \mathrm{g} / \mathrm{kg} \text {. TOGU } 12 / 29 \text { and TOGU } 2 / 198 \text { clones, on the other hand, had } 126.24 \pm 2.29 \text { and } 125.29 \pm \\
2.74 \mu \mathrm{g} / \mathrm{kg} \text { of } 4 \text {-hydroxybenzoic acid, respectively. Salicylic acid which is a pharmaceutically } \\
\text { significant compound was found in TOGU } 3 / 518 \text { clone }(125.66 \pm 11.51 \mu \mathrm{g} / \mathrm{kg}) \text { as a major product. } \\
\text { This compound was also found in TOGU } 2 / 198(111.27 \pm 1.31 \mu \mathrm{g} / \mathrm{kg}) \text { and TOGU } 12 / 29 \text { clones } \\
(111.07 \pm 3.68 \mu \mathrm{g} / \mathrm{kg}) \text { as the third and fourth most abundant. In terms of caffeic acid, TOGU } 3 / 110 \\
\text { clone contained the highest level }(42.50 \pm 3.73 \mu \mathrm{g} / \mathrm{kg}) \text {. While TOGU } 7 / 146 \text { clone included the most } \\
\text { protocatechuic acid }(53.98 \pm 1.47 \mu \mathrm{g} / \mathrm{kg}), \mathrm{TOGU} 3 / 480 \text { clone consisted of most gentisic acid }(30.79 \\
\pm 0.51 \mu \mathrm{g} / \mathrm{kg}) \text {. Quercetin, an important flavonoid found many aromatic and medicinal plants, was } \\
\text { highest in TOGU } 12 / 29 \text { clone }(6.27 \pm 0.15 \mu \mathrm{g} / \mathrm{kg}) \text {. }\end{array}$ \\
\hline
\end{tabular}

Quantitative analysis

Spectroscopy

\section{Introduction}

Potato (Solanum tuberosum L.) is one of the most important vegetable crops produced all over the world and plays a significant role in human nutrition (Ahmed et al., 2018). Potato is the carbohydrate source that has $80 \%$ water and $20 \%$ dry matter in the harvested fresh state. Potatoes, which are especially rich in vitamin $\mathrm{C}$, contain vitamins B1, B3, B6, E and minerals such as calcium, potassium, phosphorus, and magnesium (Ezekiel et al., 2013). Total phenolic content in potatoes is higher than other commonly used fruits and vegetables such as tomatoes, carrots and onions (Camire et al., 2009). Flavonoids, anthocyanins are found more in the peel than in the inner part of the potatoes (Calliope et al., 2018). Among the phenolic acids, caffeic acid and chlorogenic acid, which is the ester of quinic acid, are found abundantly in potatoes (Friedman, 1997). Potato peels contain cinnamic acid, ferulic acid, gallic acid, and protocatechuic acid in high percentage. The consumption habit of the potato has been changed recently. While the consumption of fresh potatoes is decreasing, the consumption of chips and frozen potatoes is increasing in developed countries. Potatoes are rich source of dietary energy because of their carbohydrate value and protein content. Potatoes are marketed as various forms such as chips, mashed potatoes, frozen, and dehydrated products like granules (Bergthaller et al., 1999). Phenolic compounds in the potatoes contribute to the antioxidant capacity. Especially, caffeic acid, chlorogenic acid and protocatechuic acid increase the corresponding activity of potatoes (Kähkönen et al., 1999).

Phenolic compounds, known as secondary metabolites, are complex molecules found in all plants and synthesized to protect them against bacteria, fungi, viruses, and insects (Dede et al., 2019; Koysu et al., 2019). According to their chemical structures, they are divided into groups as flavonoids, terpenoids, alkaloids, phenolic acids, tannins, stilbenes, coumarins and lignans (Singh and Saldaña, 2011). The plants synthesize various phenolic compounds with different quantity. After the discovery of spectroscopy, isolation, and identification of secondary metabolites from plants have become the focus of science (Aksit et al., 2014; Demirtas et 
al., 2013; Elmastas et al., 2004; Sahin Yaglioglu et al., 2013; Topcu et al., 1999). A great number of secondary metabolites with significant biological activities were isolated from plants (Bayir et al., 2014; Elmastas et al., 2015; Erenler et al., 2015; Erenler et al., 2014).

Environmental factors such as climate, altitude, soil and nutrients, light have considerable effects on the concentration and composition of phenolic compounds. Moreover, these environmental factors are effective on the therapeutic properties of medicinal plants (Burt 2006, Cragg et al., 1997; Kaya et al., 2014). Consequently, determination of the photochemistry of a plant by quantitative analysis is important for medicinal properties. Quantitative analysis means taking a tomographic image of the plant. After biological activity and quantitative analysis, it can be understood which compound cause the activity. Hence, modification of plants by increasing or decreasing the quantity of compounds in the plant by exposure of stress conditions would be effective for plant nutritional values (Harvey, 2010).

In this study, quantitative analysis of phenolic compounds was determined for 21 potato clones and three cultivars grown in Central Northern Region in Turkey.

\section{Materials and Methods}

\section{Materials}

In the experiment, 21 different promising potato breeding lines and 3 commercially available cultivars were used as plant material. These genotypes were grown in Tokat Artova conditions in 2020. Tokat Artova is located between $40.13^{\circ}$ north latitudes and $36.33^{\circ}$ east longitudes with an altitude of $1190 \mathrm{~m}$. The pedigrees of potato clones are shown in Table 1.

\section{Chemicals}

Gentisic acid, caffeic acid, quercetin, protocatechuic acid, 4-hydroxybenzoic acid, salicylic acid, ferulic acid, and vanillic acid were purchased from Sigma Aldrich Company. Methanol and other solvents with HPLC grade were bought from Merck.

\section{Extraction Protocol}

Potato powder of each clone (1.0 g) was extracted with methanol $(50 \%)$ and acetic acid $(0.5 \%)$ for three hours at room temperature (RT). Later, vortex process was carried out for 20 seconds at five times. The centrifugation continued at $10000 \mathrm{rpm}$ for $20 \mathrm{~min}$, then, the supernatant was taken to a new tube. The process was repeated four times and supernatants were combined. A last centrifugation was performed to remove the remaining tissue suspension and stored at deep fridge $\left(-80^{\circ} \mathrm{C}\right)$ for further analysis (Nusret et al., 2020).

\section{Chromatographic Conditions and instrumentation}

Tubers were harvested in the mid of October in Artova. After harvest, tubers were stored at $+4^{\circ} \mathrm{C}$ for 8 weeks. Quantitative analysis of phenolic compounds was carried out using Shimadzu LCMS-8050 instrument. LC-30AD binary pumps, DGU-20A3r degasser, CTO-10ASvp column oven and SIL-30AC autosampler were used for liquid chromatography. C18 Inertsil ODS-4 $(3 \mu \mathrm{m} ; 2.1 \times 150 \mathrm{~mm})$ analytical column was employed for separation. The column temperature was adjusted at $40^{\circ} \mathrm{C}$. The elution gradient contained mobile phase A (water, $5 \mathrm{mM}$ ammonium formate) and $\mathrm{B}$ (methanol, $5 \mathrm{mM}$ ammonium formate).

Table 1. Plant material used in the experiment

\begin{tabular}{|c|c|c|c|c|}
\hline Number & Clones Name & Pedigree & Tuber Flesh Color & Tuber Skin Color \\
\hline 1 & TOGU 2/503 & & White & Light Beige \\
\hline 2 & TOGU 2/198 & $\mathrm{A} 3 / 110 \times \mathrm{A} 2 / 11$ & White & Yellow \\
\hline 3 & TOGU 2/86 & & Light Yellow & Yellow \\
\hline 4 & TOGU 3/640 & & Dark Yellow & Yellow \\
\hline 5 & TOGU 3/518 & & Dark Yellow & Beige \\
\hline 6 & TOGU 3/480 & A3/15 × Bafana & Dark Yellow & Yellow \\
\hline 7 & TOGU 3/110 & & Yellow & Yellow \\
\hline 8 & TOGU 4/304 & $\Delta 7 / 12 \times \Delta 3 / 110$ & Cream & Yellow \\
\hline 9 & TOGU 4/103 & $\mathrm{A} / / 12 \times \mathrm{A} 3 / 110$ & White & White to Yellow \\
\hline 10 & TOGU $6 / 28$ & & Yellow & Yellow \\
\hline 11 & TOGU 6/329 & $\mathrm{A} 4 / 4 \times \mathrm{A} 6 / 28$ & Dark yellow & Yellow \\
\hline 12 & TOGU 6/187 & & Light Yellow & Beige \\
\hline 13 & TOGU 7/1 & & Yellow & Light Beige \\
\hline 14 & TOGU 7/10 & A2/11 × Melody & Dark Yellow & Yellow \\
\hline 15 & TOGU 7/146 & & Light Yellow & Yellow \\
\hline 16 & TOGU 8/150 & A7/12 $\times$ Van Gogh & Light Yellow & Light Beige \\
\hline 17 & TOGU 10/676 & & White/Cream & Light Beige \\
\hline 18 & TOGU 10/403 & Bascitflik Beyazi × A13/1 & White turp & Light Beige \\
\hline 19 & TOGU $10 / 487$ & & White & White to Yellow \\
\hline 20 & TOGU 12/29 & Bascitflik Beyazi $\times$ Van Gogh & Dark Yellow & Yellow \\
\hline 21 & TOGU $14 / 353$ & Alleddiyan Sarıs1 $\times$ A2/11 & Dark Yellow & Yellow \\
\hline 22 & Agata & & Light yellow & White to Yellow \\
\hline 23 & Agria & & Dark Yellow & White to Yellow \\
\hline 24 & Basciftlik Beyazi & & White & White to Yellow \\
\hline
\end{tabular}


The programme was applied as $\mathrm{B}(\mathrm{t}, \mathrm{min}), \mathrm{B} \%:(0-8$, 95), (8.01-12, 95), (12.01-15, 5). The flow rate of solvent was set as $0.4 \mathrm{ml} / \mathrm{min}$, and injection volume was $20 \mu \mathrm{l}$. Shimadzu LCMS 8050 model triple quadrupole mass spectrometer equipped with an ESI source operating in positive and negative ionization mode were used for MS detection. The optimum ESI conditions were fixed as interface temperature; $300^{\circ} \mathrm{C}$, DL temperature; $250^{\circ} \mathrm{C}$, heat block temperature; $400^{\circ} \mathrm{C}$, nebulizing gas flow (nitrogen); $101 \mathrm{~min}^{-1}$ and drying gas flow (nitrogen); $151 \mathrm{~min}^{-1}$ LabSolutions software (Shimadzu, Kyoto, Japan) was used for data collection.

\section{Validation and Quantitative Analysis}

Firstly, optimisation was performed for spectrometric and chromatographic conditions. Various column, mobile phases (acetonitrile-water, methanol-water etc.), stationary phase (ammonium acetate, ammonium formate-formic acid), column temperature and flow rate were optimized for the best chromatographic separation and mass ionization efficiencies.

\section{Linearity}

A calibration study was performed showing important phenolic compounds over a wide range of concentrations. Six concentrations were used for the linearity studies of each analysis, and each concentration was performed in triplicate. The method applied indicated to be linear for all compounds for tested concentration while the validation of the method $\left(\mathrm{R}^{2} \geq 0.990\right)$ (Table 2$)$.

\section{Accuracy (Recovery) and Precision (Repeatability)}

The precision and accuracy were determined by standard addition to the selected potato clone extract. Intraday and inter-day variability evaluations were executed. For intra-day variability, spiked samples were measured in five replicates in a single day and for inter-day variability, spiked samples were examined in five replicates per day for five consecutive days. Hence, recovery and \%RSD values were calculated to present the accuracy and precision (Table 2).

\section{Detection and Quantification Limits (LOD/LOQ)}

The analysis mixture was spiked at ten identical samples prepared from selected extract at the lowest concentration by the standards to determine the LOD and LOQ values (Table 2).

\section{Results and Discussion}

In addition to showing antioxidant properties, polyphenols have a wide range of biological activities and are the most numerous antioxidants in our diet. The polyphenol compounds in potato make it important in the daily diet (Wierzbicka et al., 2015).

After validation of the method, the phenolic composition of different potato clones methanolic extracts were investigated by the developed and validated LC-MS/MS method. The standard compounds are given in Figure 1. The 2/503 clone which was obtained by hybridisation of A3/110 $\times$ A2/11 contained three compounds; the major product was 4-hydroxybenzoic acid with the value of $23.11 \pm 1.02$ $(\mu \mathrm{g} / \mathrm{kg})$. TOGU 8/150 clone consisted of only two phenolics and 4-hydroxybenzoic acid was detected as the chief compound (5.61 \pm 0.30$)$. Another clone, TOGU 14/353 consisted of four phenolic compounds among the tested ones and 4-hydroxylbenzoic acid was also detected as the main product $(31.31 \pm 1.48)$. 4-hydroxy benzoic acid was found as the chief product in TOGU 4/304 clone $(68.17 \pm 1.12)$. The clones TOGU 3/640 and TOGU 3/518 contained the 8 and 9 compounds, respectively. 4-hydroxybenzoic acid was the chief product in both clones. While the 4-benzoic acid concentration was found in the former clone as $82.37 \pm 4.15$ $\mu \mathrm{g} / \mathrm{kg}$, it was found in later clone as $138.51 \pm 7.35$ which was the highest concentration among the tested standards. The other clones called TOGU 2/198 and TOGU 7/146 contained the five tested standard compounds. While 4benzoic acid was the most abundant compound in clone TOGU 2/198, protocatechuic acid was the main compound in $7 / 146$. The clone $7 / 1$ and clone $3 / 480$ also consisted of five compounds. The chief compound, 4-benzoic acid concentration was found in corresponding clones as $36.56 \pm$ $4.15 \mu \mathrm{g} / \mathrm{kg}$ and $59.54 \pm 2.33 \mu \mathrm{g} / \mathrm{kg}$, respectively. TOGU 3/110 and TOGU 12/29 clones included the six and five compounds, respectively. The 4- benzoic acid concentration was the major compounds in clone TOGU 12/29 with the value of $126.24 \pm 2.29 \mu \mathrm{g} / \mathrm{kg}$. The clone TOGU 3/110 included the caffeic acid and the chief product $(42.50 \pm 3.73$ $\mu \mathrm{g} / \mathrm{kg}$ ). The clones TOGU 10/403, TOGU 6/28 and TOGU $10 / 676$ contained the 4-benzoic acid as the major compound. 4-hydroxybenzioic acid was found as a major product in TOGU 7/F10, TOGU 6/187 and TOGU 10/487 clones as well. The quantitative analysis of phenolic compounds was also investigated in Agata, Basciftlik Beyazi and Agria cultivars. 4-hydroxybenzoic acid was the major compound in Agata. However, Basciftlik Beyazi contained only two compounds. Interestingly, Agria contained gallic acid which was not found in tested clones and cultivars. 4hydroxybenzoic acid was found as a major compound in all tested materials except three materials (one cultivar and two clones) (Table 3).

Previously reported work indicated that phenolic acids are the most abundant compounds in potatoes. Chlorogenic acid, caffeic acid, vanillic acid, protocatechuic acid, ferulic acid were the main compounds of potatoes in different concentrations (Akyol et al., 2016) and these results were similar to our study. A quantitative study was carried out on four potato cultivars and chlorogenic acid, caffeic acid, ferulic acid, $p$-coumaric acid, trans-cinnamic acid were found as the main products (Im et al., 2008).

The clones include the considerable protocatechuic acid (3,4-dihydroxybenzoic acid) which is a phenolic compound found in many food plants. PCA is the main metabolite of anthocyanins which can reduce the risk of cardiovascular diseases. The beneficial effect of anthocyanins is partly due to the revealing a considerable activity such as anti-inflammatory, antioxidant, peroxidation inhabitation effects. PCA was reported to have pharmaceutical properties such as antioxidant, antimicrobial, anti-inflammatory, antihyperglycemia, antiapoptosis activities (Semaming et al., 2015).

The other secondary metabolite present in clones is 4hydroxybenzoic acid, a biodegradable bioactive natural product isolated from carrots, oil palm, grapes, peroba, taheebo, red sandalwood, southern catalpa, Chinese chest, palm, medlar. 4-hydroxybenzoic acid revealed the antibacterial, antifungal, antialgal, antimutagenic, estrogenic activities. (Khadem and Marles, 2010) 
Table 2. Analytical parameters that belong to the LC-MS/MS method

\begin{tabular}{|c|c|c|c|c|c|c|c|c|c|c|c|}
\hline \multirow{2}{*}{$\mathrm{PC}$} & \multirow{2}{*}{ RT } & \multirow{2}{*}{ PI } & \multirow{2}{*}{ Product ions } & \multirow{2}{*}{$\mathrm{CE}$} & \multirow{2}{*}{$\mathrm{R}^{2}$} & \multirow{2}{*}{ LOD } & \multirow{2}{*}{ LOQ } & \multicolumn{2}{|c|}{ Recovery \% } & \multicolumn{2}{|c|}{ RSD \% } \\
\hline & & & & & & & & Inter-day & Intra-day & Inter-day & Intra-day \\
\hline $4 \mathrm{HBA}$ & 4.403 & 137.20 & $93.10 / 65.10$ & $17.0 / 24.0$ & 0.990 & 1.68 & 5.61 & 111.05 & 109.67 & 3.34 & 3.05 \\
\hline SA & 4.384 & 137.20 & 93.10 & 18.0 & 0.993 & 1.18 & 3.93 & 102.05 & 102.35 & 6.30 & 3.33 \\
\hline CA & 2.776 & 179.00 & $134.10 / 117.10 / 109.00$ & $13.0 / 23.0 / 10.0$ & 0.999 & 0.82 & 2.74 & 3.95 & & 14.42 & 9.08 \\
\hline PCA & 2.855 & 153.10 & $108.90 / 108.10$ & $20.0 / 11.0$ & 0.999 & 3.48 & 11.60 & 98.45 & 105.48 & 11.24 & 7.50 \\
\hline GA & 2.895 & 153.00 & $108, .0$ & 2.0 & 0.999 & 1.08 & 3.60 & 110.35 & 106.07 & 6.02 & 7.45 \\
\hline QUE & 7.561 & 300.90 & $151.10 / 212.10 / 107.10$ & $15.0 / 24.0 / 20.0$ & 0.997 & 1.64 & 5.46 & 96.20 & 96.26 & 8.06 & 8.52 \\
\hline FA & 3.884 & 193.00 & & $24.0 / 20.0$ & & 2.7 & & & & 10.37 & 13.21 \\
\hline VA & & & & .0 & & 4.1 & 13 & 99.50 & 92.81 & 9.57 & 19.58 \\
\hline CHA & 3.658 & 352.90 & $1.10 / 127.10$ & $20.0 / 25.0$ & 0.999 & 1.83 & 6. & 96.45 & 98.01 & 7.88 & 7.77 \\
\hline GAA & 1.149 & 169.10 & $125.20 / 79.0$ & $24.0 / 30.0$ & 0.992 & 1.73 & 5.77 & 100.15 & 96.72 & 5.09 & 4.48 \\
\hline
\end{tabular}

PC: Phenolic compound, PI: Precursor ion, 4HBA: 4-hydroxybenzoic acid, SA: salicylic acid, CA: caffeic acid, PCA: protocatechuic acid, GA: gentisic acid, QUE: quercetin, FA: ferulic acid, VA: vanillic acid, CHA: chlorgenic acid, GAA: gallic acid, RT: Retention time (min), Precursor ion $(m / z)$ : Molecular ions of the standard compounds ( $\mathrm{m} / \mathrm{z}$ ratio), CE: Collision energy (eV), $\mathrm{R}^{2}$ : Coefficient of determination, RSD: Relative standard deviation, $\mathrm{LOD} / \mathrm{LOQ}(\mu \mathrm{g} / \mathrm{L})$ : Limit of detection/quantification

Table 3. Quantitative analysis of the potato promising clones and cultivars

\begin{tabular}{|c|c|c|c|c|c|c|c|c|c|c|}
\hline \multirow{2}{*}{ Clone } & \multicolumn{2}{|c|}{ 4HBA } & \multicolumn{2}{|c|}{ SA } & \multicolumn{2}{|c|}{$\mathrm{CA}$} & \multicolumn{2}{|c|}{ PCA } & \multicolumn{2}{|c|}{ GA } \\
\hline & $\mathrm{M}$ & SD & $\mathrm{M}$ & SD & $\mathrm{M}$ & SD & $\mathrm{M}$ & SD & $\mathrm{M}$ & SD \\
\hline TOGU 2/503 & 23.11 & 1.02 & 20.74 & 1.51 & $<\mathrm{LOD}$ & & $<\mathrm{LOD}$ & & $<\mathrm{LOD}$ & \\
\hline TOGU 8/150 & 5.61 & 0.30 & $<\mathrm{LOD}$ & & 4.92 & 0.93 & $<\mathrm{LOD}$ & & $<\mathrm{LOD}$ & \\
\hline TOGU $14 / 353$ & 31.31 & 1.48 & 28.60 & 1.51 & 5.16 & 0.63 & $<$ LOD & & $<\mathrm{LOD}$ & \\
\hline TOGU 4/304 & 68.17 & 1.12 & 62.09 & 0.50 & 6.80 & 0.46 & $<\mathrm{LOD}$ & & $<\mathrm{LOD}$ & \\
\hline TOGU 3/640 & 82.37 & 4.15 & 73.45 & 5.27 & 21.70 & 1.09 & 20.25 & 1.10 & 30.08 & 1.27 \\
\hline TOGU 3/518 & 138.51 & 7.35 & 125.66 & 11.51 & 18.18 & 0.69 & 18.43 & 1.11 & 23.75 & 0.99 \\
\hline TOGU 2/198 & 125.29 & 2.74 & 111.27 & 1.31 & 31.26 & 5.62 & 10.66 & 1.76 & 9.10 & 0.56 \\
\hline TOGU 7/146 & 44.73 & 1.09 & 42.59 & 1.24 & 8.52 & 1.04 & 53.98 & 1.47 & 25.62 & 0.94 \\
\hline TOGU 7/1 & 36.56 & 1.94 & 33.41 & 1.19 & 11.64 & 0.37 & 9.62 & 0.71 & 9.82 & 1.14 \\
\hline TOGU 3/480 & 59.54 & 2.33 & 53.88 & 2.66 & 4.53 & 1.03 & 18.91 & 2.73 & 30.79 & 0.51 \\
\hline TOGU 3/110 & 9.20 & 0.79 & 8.42 & 0.14 & 42.50 & 3.73 & 9.75 & 1.48 & $<\mathrm{LOD}$ & \\
\hline TOGU 12/29 & 126.24 & 2.29 & 111.07 & 3.68 & 6.96 & 1.06 & 13.80 & 2.27 & $<\mathrm{LOD}$ & \\
\hline TOGU $10 / 403$ & 9.31 & 0.22 & 8.50 & 0.04 & 5.75 & 0.21 & $<\mathrm{LOD}$ & & $<\mathrm{LOD}$ & \\
\hline TOGU 6/28 & 7.04 & 0.67 & 6.67 & 0.55 & 4.25 & 0.18 & $<\mathrm{LOD}$ & & $<\mathrm{LOD}$ & \\
\hline TOGU $10 / 676$ & 13.52 & 0.43 & 12.52 & 0.79 & 5.72 & 1.07 & $<\mathrm{LOD}$ & & 5.99 & 0.49 \\
\hline TOGU 7/F10 & 71.03 & 1.15 & 62.57 & 1.93 & $<\mathrm{LOD}$ & & 19.86 & 1.68 & 11.84 & 0.18 \\
\hline TOGU 6/187 & 44.04 & 1.04 & 41.07 & 0.44 & $<\mathrm{LOD}$ & & 7.38 & 0.18 & $<\mathrm{LOD}$ & \\
\hline TOGU 10/487 & 44.45 & 1.63 & 39.16 & 0.71 & $<\mathrm{LOD}$ & & 5.72 & 0.54 & $<\mathrm{LOD}$ & \\
\hline TOGU 6/329 & 14.88 & 0.70 & 11.97 & 0.94 & 10.67 & 1.61 & $<\mathrm{LOD}$ & & $<\mathrm{LOD}$ & \\
\hline TOGU 4/103 & 13.95 & 0.18 & 13.28 & 1.07 & 4.00 & 0.10 & $<\mathrm{LOD}$ & & $<$ LOD & \\
\hline TOGU 2/86 & $<\mathrm{LOD}$ & & $<\mathrm{LOD}$ & & 4.53 & 0.49 & $<\mathrm{LOD}$ & & $<\mathrm{LOD}$ & \\
\hline Agata & 67.50 & 2.91 & 59.37 & 2.45 & $<\mathrm{LOD}$ & & $<\mathrm{LOD}$ & & 23.28 & 1.72 \\
\hline Agria & $<\mathrm{LOD}$ & & $<\mathrm{LOD}$ & & 6.67 & 1.03 & $<\mathrm{LOD}$ & & $<\mathrm{LOD}$ & \\
\hline B.Beyazi & 4.40 & 0.31 & $<\mathrm{LOQ}$ & & $<$ LOD & & $<$ LOD & & $<\mathrm{LOD}$ & \\
\hline \multirow{2}{*}{ Clone } & \multicolumn{2}{|c|}{ QUE } & \multicolumn{2}{|c|}{ FA } & \multicolumn{2}{|l|}{ VA } & \multicolumn{2}{|l|}{ CHA } & \multicolumn{2}{|c|}{ GAA } \\
\hline & $\mathrm{M}$ & SD & M & SD & $\mathrm{M}$ & SD & $\mathrm{M}$ & SD & $\mathrm{M}$ & SD \\
\hline TOGU 2/503 & $<\mathrm{LOD}$ & & 5.70 & 1.16 & $<\mathrm{LOD}$ & & $<\mathrm{LOD}$ & & $<\mathrm{LOD}$ & \\
\hline TOGU 8/150 & $<\mathrm{LOD}$ & & $<\mathrm{LOD}$ & & $<\mathrm{LOD}$ & & $<\mathrm{LOD}$ & & $<\mathrm{LOD}$ & \\
\hline TOGU $14 / 353$ & 5.00 & 0.55 & $<\mathrm{LOD}$ & & $<\mathrm{LOD}$ & & $<\mathrm{LOD}$ & & $<\mathrm{LOD}$ & \\
\hline TOGU 4/304 & $<\mathrm{LOD}$ & & $<\mathrm{LOD}$ & & $<\mathrm{LOD}$ & & $<\mathrm{LOD}$ & & $<\mathrm{LOD}$ & \\
\hline TOGU 3/640 & $<\mathrm{LOD}$ & & 30.65 & 2.47 & 28.84 & 2.79 & 11.05 & 1.27 & $<\mathrm{LOD}$ & \\
\hline TOGU 3/518 & 5.45 & 0.19 & 6.11 & 0.22 & 11.60 & 0.75 & 6.71 & 0.54 & $<\mathrm{LOD}$ & \\
\hline TOGU 2/198 & $<\mathrm{LOD}$ & & $<\mathrm{LOD}$ & & $<\mathrm{LOD}$ & & $<\mathrm{LOD}$ & & $<\mathrm{LOD}$ & \\
\hline TOGU 7/146 & $<\mathrm{LOD}$ & & $<\mathrm{LOD}$ & & $<\mathrm{LOD}$ & & $<\mathrm{LOD}$ & & $<\mathrm{LOD}$ & \\
\hline TOGU 7/1 & $<$ LOD & & $<$ LOD & & $<$ LOD & & $<$ LOD & & $<$ LOD & \\
\hline TOGU 3/480 & $<\mathrm{LOD}$ & & $<\mathrm{LOD}$ & & $<\mathrm{LOD}$ & & $<\mathrm{LOD}$ & & $<\mathrm{LOD}$ & \\
\hline TOGU 3/110 & $<$ LOD & & $<\mathrm{LOD}$ & & $<\mathrm{LOD}$ & & 6.71 & 0.31 & $<\mathrm{LOD}$ & \\
\hline TOGU 12/29 & 6.27 & 0.15 & $<\mathrm{LOD}$ & & $<\mathrm{LOD}$ & & $<\mathrm{LOD}$ & & $<\mathrm{LOD}$ & \\
\hline TOGU $10 / 403$ & 5.57 & 0.57 & $<\mathrm{LOD}$ & & $<\mathrm{LOD}$ & & $<\mathrm{LOD}$ & & $<\mathrm{LOD}$ & \\
\hline TOGU 6/28 & $<\mathrm{LOD}$ & & $<\mathrm{LOD}$ & & $<\mathrm{LOD}$ & & $<\mathrm{LOD}$ & & $<\mathrm{LOD}$ & \\
\hline TOGU $10 / 676$ & $<\mathrm{LOD}$ & & $<\mathrm{LOD}$ & & $<\mathrm{LOD}$ & & $<\mathrm{LOD}$ & & $<\mathrm{LOD}$ & \\
\hline TOGU 7/F10 & $<\mathrm{LOD}$ & & $<\mathrm{LOD}$ & & $<\mathrm{LOD}$ & & $<\mathrm{LOD}$ & & $<\mathrm{LOD}$ & \\
\hline TOGU 6/187 & 4.46 & 0.18 & $<\mathrm{LOD}$ & & $<\mathrm{LOD}$ & & $<\mathrm{LOD}$ & & $<\mathrm{LOD}$ & \\
\hline TOGU $10 / 487$ & 5.47 & 0.35 & $<\mathrm{LOD}$ & & $<\mathrm{LOD}$ & & $<\mathrm{LOD}$ & & $<\mathrm{LOD}$ & \\
\hline TOGU 6/329 & $<$ LOD & & $<\mathrm{LOD}$ & & $<\mathrm{LOD}$ & & $<\mathrm{LOD}$ & & $<\mathrm{LOD}$ & \\
\hline TOGU 4/103 & $<\mathrm{LOD}$ & & $<\mathrm{LOD}$ & & $<\mathrm{LOD}$ & & $<\mathrm{LOD}$ & & $<\mathrm{LOD}$ & \\
\hline TOGU 2/86 & $<\mathrm{LOD}$ & & $<\mathrm{LOD}$ & & $<\mathrm{LOD}$ & & $<\mathrm{LOD}$ & & $<\mathrm{LOD}$ & \\
\hline Agata & $<\mathrm{LOD}$ & & $<\mathrm{LOD}$ & & $<\mathrm{LOD}$ & & $<\mathrm{LOD}$ & & $<\mathrm{LOD}$ & \\
\hline Agria & $<\mathrm{LOD}$ & & $<\mathrm{LOD}$ & & $<\mathrm{LOD}$ & & $<\mathrm{LOD}$ & & 7.32 & 0.16 \\
\hline B.Beyazi & $<\mathrm{LOD}$ & & $<\mathrm{LOD}$ & & $<\mathrm{LOD}$ & & $<\mathrm{LOD}$ & & $<\mathrm{LOD}$ & \\
\hline
\end{tabular}

4HBA: 4-hydroxybenzoic acid, SA: salicylic acid, CA: caffeic acid, PCA: protocatechuic acid, GA: gentisic acid, QUE: quercetin, FA: ferulic acid, VA: vanillic acid, CHA: chlorgenic acid, GAA: gallic acid, M: Mean, SD: Standard deviation, LOD: Limit of detection, LOQ: Limit of quantification. 

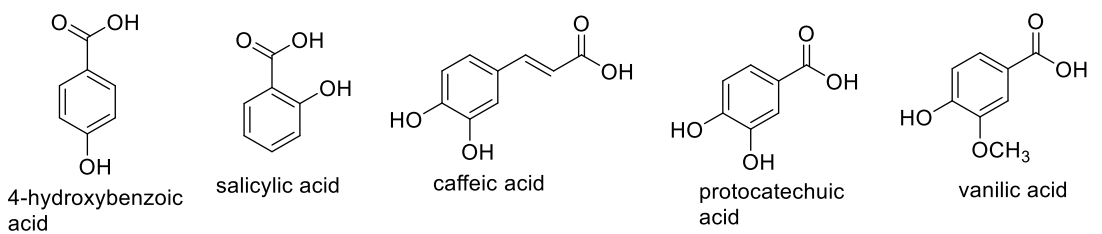

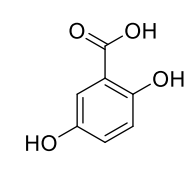

gentisic acid
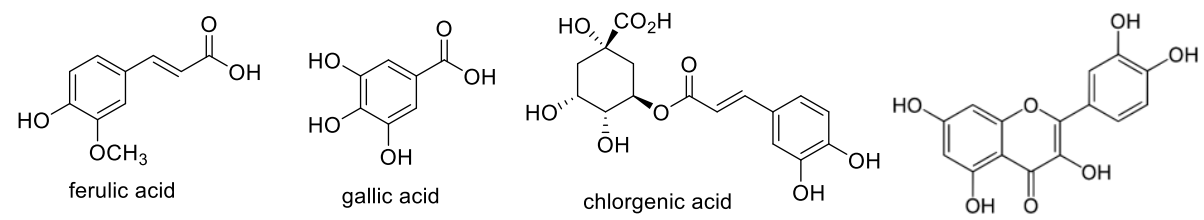

Figure 1. The standard phenolic compounds for quantitative analysis

Gentisic acid (2,5-dihydroxy benzoic acid) are found in plant kingdom plentifully. Gentisic acid has analgesic, anti-inflammatory, antirheumatic, antiarthritic and cytostatic effects, and inhibits low-density lipoprotein oxidation in human plasma (Ashidate et al 2005).

The clones include salicylic acid (2-hydroxy benzoic acid) also found in many aromatic and medicinal plants. Moreover, it is produced by the bacterium Pseudomonas cepacia. It has anti-inflammatory, analgesic, antifungal, keratolytic, antipyretic activities (Ashidate et al 2005).

Caffeic acid (3,4-dihydroxy cinnamic acid) is the metabolite occur in plant kingdoms commonly. This compound is present in many foods such as coffee drinks, blueberries, cider, and apples. In addition, it is found in propolis. Caffeic acid was reported to have anticancer, antioxidant, antibacterial properties. Moreover, it can contribute to inhabitation of atherosclerosis and various cardiovascular diseases (Magnani et al 2014).

\section{Conclusion}

Photochemical properties of 21 potato promising clones and 3 commercial cultivars of Solanum tuberosum L. were displayed. Quantitative analysis results of clones and cultivars will be a significant data for potatoes researchers because these kinds of studies will enable us to reveal the best quality of potatoes containing certain quantities of phenolic compounds. Since $3 / 518$ clone included the most phenolic compounds, it could be preferred for production on a large scale.

\section{References}

Ahmed S, Zhou X, Pang Y, Xu Y, Tong C, Bao J. 2018. Genetic diversity of potato genotypes estimated by starch physicochemical properties and microsatellite markers. Food Chemistry. 257: 368-75.

Akyol H, Riciputi Y, Capanoglu E, Caboni MF, Verardo V. 2016. Phenolic compounds in the potato and its byproducts: an overview. International journal of molecular sciences. 17: 835.

Aksit H, Çelik SM, Sen Ö, Erenler R, Demirtas I, et al. 2014. Complete isolation and characterization of polar portion of Mentha dumetorum water extract. Records of Natural Products. 8: 277-80.

Ashidate K, Kawamura M, Mimura D, Tohda H, Miyazaki S, et al. 2005. Gentisic acid, an aspirin metabolite, inhibits oxidation of low-density lipoprotein and the formation of cholesterol ester hydroperoxides in human plasma. European journal of pharmacology. 513: 173-79.
Bayir B, Gündüz H, Usta T, Şahin E, Özdemir Z, et al. 2014. Chemical Composition of Essential Oil from Marrubium Vulgare L. Leaves. Journal of New Results in Science. 6: 4450 .

Bergthaller W, Witt W, Goldau HP. 1999. Potato starch technology. Starch-Stärke. 51: 235-42.

Burt J. 2006. Natural Products in Drug Discovery \& Development II - 2nd Annual Taylor \& Francis Conference 21-22 June 2006, London, UK. Idrugs. 9: 607-09.

Calliope SR, Lobo MO, Sammán NC. 2018. Biodiversity of Andean potatoes: Morphological, nutritional and functional characterization. Food Chemistry. 238: 42-50.

Camire ME, Kubow S, Donnelly DJ. 2009. Potatoes and human health. Critical reviews in food science and nutrition. 49: 82340.

Cragg GM, Newman DJ, Snader KM. 1997. Natural products in drug discovery and development. Journal of Natural Products. 60: 52-60.

Dede E, Genc N, Elmastas M, Aksit H, Erenler R. 2019. Chemical Constituents Isolated from Rhododendron ungernii with Antioxidant Profile. The Natural Products Journal. 9: 238-43.

Demirtas I, Erenler R, Elmastas M, Goktasoglu A. 2013. Studies on the antioxidant potential of flavones of Allium vineale isolated from its water-soluble fraction. Food Chemistry. 136: 34-40.

Elmastas M, Ozturk L, Gokce I, Erenler R, Aboul-Enein HY. 2004. Determination of antioxidant activity of marshmallow flower (Althaea officinalis L.). Analytical Letters. 37: 185969.

Elmastas M, Telci İ, Akşit H, Erenler R. 2015. Comparison of total phenolic contents and antioxidant capacities in mint genotypes used as spices/Baharat olarak kullanılan nane genotiplerinin toplam fenolik içerikleri ve antioksidan kapasitelerinin karşılaştırılması. Turkish Journal of Biochemistry. 40: 456-62.

Erenler R, Telci I, Ulutas M, Demirtas I, Gul F, et al. 2015. Chemical Constituents, Quantitative Analysis and Antioxidant Activities of Echinacea purpurea (L.) Moench and Echinacea pallida (Nutt.) Nutt. Journal of Food Biochemistry. 39: 622-30.

Erenler R, Yilmaz S, Aksit H, Sen O, Genc N, et al. 2014. Antioxidant activities of chemical constituents isolated from Echinops orientalis Trauv. Records of Natural Products. 8: 32-36.

Ezekiel R, Singh N, Sharma S, Kaur A. 2013. Beneficial phytochemicals in potato-a review. Food Research International. 50: 487-96.

Friedman M. 1997. Chemistry, biochemistry, and dietary role of potato polyphenols. A review. Journal of Agricultural and Food Chemistry. 45: 1523-40.

Harvey A. 2010. The role of Natural Products in Drug Discovery and development in the New Millennium. Idrugs. 13: 70-72. 
Im HW, Suh B-S, Lee S-U, Kozukue N, Ohnisi-Kameyama M, et al. 2008. Analysis of phenolic compounds by highperformance liquid chromatography and liquid chromatography/mass spectrometry in potato plant flowers, leaves, stems, and tubers and in home-processed potatoes. Journal of Agricultural and Food Chemistry. 56: 3341-49.

Kähkönen MP, Hopia AI, Vuorela HJ, Rauha J-P, Pihlaja K, et al. 1999. Antioxidant activity of plant extracts containing phenolic compounds. Journal of Agricultural and Food Chemistry. 47: 3954-62.

Kaya G, Karakaya R, Tilgel E, Sandikci M, Yucel E, et al. 2014. Essential Oil Constituents of Thuja orientalis Berries. Journal of New Results in Science. 7: 1-6.

Khadem S, Marles RJ. 2010. Monocyclic phenolic acids; hydroxy-and polyhydroxybenzoic acids: occurrence and recent bioactivity studies. Molecules. 15: 7985-8005.

Koysu P, Genc N, Elmastas M, Aksit H, Erenler R. 2019. Isolation, identification of secondary metabolites from Salvia absconditiflora and evaluation of their antioxidative properties. Natural Product Research. 33: 3592-95.

Magnani C, Isaac VLB, Correa MA, Salgado HRN. 2014. Caffeic acid: a review of its potential use in medications and cosmetics. Analytical Methods. 6: 3203-10.
Nusret G, Elmastas M, Telci I, Erenler R. 2020. Quantitative analysis of phenolic compounds of commercial basil cultivars (Ocimum basilicum L.) by LC-TOF-MS and their antioxidant effects. International Journal of Chemistry and Technology. 4: 179-84.

Sahin Yaglioglu A, Akdulum B, Erenler R, Demirtas I, Telci I, Tekin S. 2013. Antiproliferative activity of pentadeca-(8E, 13Z) dien-11-yn-2-one and (E)-1,8-pentadecadiene from Echinacea pallida (Nutt.) Nutt. roots. Medicinal Chemistry Research. 22: 2946-53.

Semaming Y, Pannengpetch P, Chattipakorn SC, Chattipakorn N. 2015. Pharmacological properties of protocatechuic acid and its potential roles as complementary medicine. EvidenceBased Complementary and Alternative Medicine. 2015: Article ID 593902.

Singh PP, Saldaña MD. 2011. Subcritical water extraction of phenolic compounds from potato peel. Food Research International. 44: 2452-58.

Topcu G, Erenler R, Çakmak O, Johansson CB, Çelik C, et al. 1999. Diterpenes from the berries of Juniperus excelsa. Phytochemistry. 50: 1195-99.

Wierzbicka A, Hallmann E, Grudzińska M. 2015. Polyphenol content of potatoes depending on the variety and effective microorganisms. Fragmenta Agronomica. 32: 81-88. 